\title{
LEI 10.639/2003 QUESTÕES RACIAIS E IDENTITÁRIAS: uma irrevogável ação política, um diálogo necessário na educação básica'
}

\author{
Reginaldo Ferreira Domingos²
}

\section{RESUMO}

A propositura apresentada é parte de uma pesquisa em andamento no âmbito da Universidade Federal do Cariri - UFCA. A proposta de estudo aqui apresentada objetiva analisar o processo de implementação e a abordagem da Lei 10.639/2003 nas escolas públicas municipais da cidade de Brejo Santo, município caririense do interior do Ceará. Tendo como problemática: Analisar os estudos e as práticas abordadas nas escolas de ensino infantil e fundamental acerca da inserção da Lei 10.639/2003, investigar como essa questão vem sendo tratada na ação docente e a, consequente, receptividade por parte do corpo discente. No primeiro momento da ação metodológica foram realizados estudos teóricos e visitas em campo, este último visando observar o ambiente da pesquisa na busca de compreender a logística da organização espacial e as disposições imagéticas e decorativas das escolas. Neste segundo momento, a pesquisa encontra-se em fase de investigação de coleta de dados com a utilização de ferramentas como entrevistas e aplicação de questionários no intuito de entender as ações adotadas pelos professores/as nas escolas.

Palavras-chave: História. Educação Básica. Lei 10.639/2003.

\section{LAW 10.639/2003 RACIAL AND IDENTITY ISSUES:}

\section{an irrevolvable political action, a dialogue necessary in basic education}

\section{ABSTRACT}

The presented proposal is part of an ongoing research in the scope of the Federal University of Cariri - UFCA. The study proposal presented here aims to analyze the implementation process and the approach of Law 10.639 / 2003 in the municipal

\footnotetext{
1 Este artigo faz parte do Programa Institucional de Bolsas de Iniciação Científica (PIBIC), com o apoio do Conselho Nacional de Desenvolvimento Científico e Tecnológico (CNPq), no âmbito da Universidade Federal do Cariri (UFCA). Possui duas bolsistas de IC a frente na coleta, catalogação das entrevistas e das imagens. A pesquisa foi apresentada e parcialmente publicada em congressos e seminários, porém como se encontra em andamento, novas informações estão sendo coletadas e, por conseguinte, inseridas nesta propositura.

2 Doutor em Educação - Universidade Federal do Ceará - UFC. Professor do Curso de Licenciatura Interdiscplinar em Ciências Naturais e Matemática da Universidade Federal do Cariri - UFCA. Orcid iD: https://orcid.org/0000-0002-1205-5063. E-mail: reginaldo.domingos@ufca.edu.br
} 
public schools of the city of Brejo Santo, municipality of Cariri in the interior of Ceará. Having as problematic: To analyze the studies and practices addressed in primary and secondary schools about the insertion of Law 10.639 / 2003, to investigate how this issue is being treated in the teaching action and, consequently, receptivity on the part of the student body. The first moment of the methodological action was realized theoretical studies and visits in the field, the latter aiming to observe the research environment in the quest to understand the logistics of spatial organization and the imagery and decorative dispositions of the schools. In this second moment, the research is in the research phase of data collection with the use of tools such as interviews and application of questionnaires in order to understand the actions adopted by teachers in schools.

Keywords: History. Basic Education. Law 10.639/2003.

\section{LEY 10.639 / 2003 CUESTIONES RACIALES E IDENTIRAS:}

\section{una irrevogable acción política, un diálogo necesario en la educación}

\section{básica}

\section{RESUMEN}

La proposición presentada es parte de una investigación en marcha en el ámbito de la Universidad Federal del Cariri - UFCA. La propuesta de estudio aquí presentada objetiva analizar el proceso de implementación y el abordaje de la Ley 10.639 / 2003 en las escuelas públicas municipales de la ciudad de Brejo Santo, municipio caririense del interior de Ceará. En el caso de las escuelas de enseñanza infantil y fundamental acerca de la inserción de la Ley 10.639 / 2003, examinar cómo se trata en la acción docente y la consecuente, receptividad por parte del alumnado. El primer momento de la acción metodológica se realizaron estudios teóricos y visitas en campo, este último visando observar el ambiente de la investigación en la búsqueda de comprender la logística de la organización espacial y las disposiciones imagéticas y decorativas de las escuelas. En este segundo momento, la investigación se encuentra en fase de investigación de recolección de datos con la utilización de herramientas como entrevistas y aplicación de cuestionarios con el fin de entender las acciones adoptadas por los profesores / as en las escuelas.

Palabras clave: Historia. Educación básica. Ley 10.639 / 2003.

\section{INTRODUÇÃO: TECENDO CONTEXTO POLÍTICO, HISTÓRICO-SOCIAL}

É fundamental o papel da escola na
edificação do conceito, na formação do
humano, na descolonização do fazer
educação, na luta contra o racismo,
homofobia, lesbofobia, machismo,
xenofobia e qualquer tipo de
preconceito. O lócus escolar é lugar de

Revista Exitus, Santarém/PA, Vol. 9, № 5, p. 22 - 46, Edição Especial 2019. 
combater essas atitudes. É nela que constrói, no aprendiz, novos significados, leitura de mundo, amplia desenvolvimento cognitivo, amadurece o respeito da diferença (DOMINGOS; OLIVIERA, 2017).

Na sociedade brasileira durante mais de três séculos foi negado o direito fundamental à população negra e de todo e qualquer ser humano, de ir e vir. O cerceamento à liberdade e, por conseguinte, a não participação na sociedade como ser humano foi durante muito tempo a forma de controlar e impedir a ascensão social e a atuação do negro na sociedade. Durante o período escravista a negação à liberdade e a consequente, não participação social refletiram no presente uma maior dificuldade da inserção do negro no seio social (CUNHA Jr., 2011; DCN, 2004). Pois, "sabe-se que, desde o início de nossa construção histórica, o negro foi alijado das atividades públicas [e outras tarefas] ${ }^{3}$ e lhe foi imposta a dura realidade de escravo a serviço do Brasil Colônia e do Império, que surgiu à risca as determinações lusitanas" (FILGUEIRA, 2008, p. 33).

A existência negada, as expiações sofridas, a amputação, ou porque não dizer, a castração total dos direitos de ser da população africana e afrodescendente, existente no sistema desumano, em que se usava a mãode-obra de negros vindos da África, gerou na atualidade uma gama de pessoas que não se enquadram naquilo que podemos chamar de cidadão. Essa negação se deu pela ação do racismo anti-negro que foi e é danoso aos africanos e africanas e aos seus descendentes na atualidade.

Esse modelo de ser cidadão que dá base para uma ação transformadora foi negado aos negros, grupos sociais marcados por discriminações raciais e pela exclusão social. Logo, tanto a forma cidadã de ser e a educação para a população negra tem sido subtraída por um grupo dominante e racista que controla as relações de poderes. O modelo hegemônico racista está, simbolicamente, representado nos espaços educativos institucionalizados. Esse molde permite a perpetuação do poder

\footnotetext{
${ }^{3}$ Grifo nosso.
}

Revista Exitus, Santarém/PA, Vol. 9, № 5, p. 22 - 46, Edição Especial 2019. 
de uma elite branca contrária à cidadania da população afrodescendente (CUNHA Jr., 2007; MUNANGA; GOMES, 2004).

Portanto, essa relação de poder construída pelo grupo dominante desvirtua e continua a distorcer a realidade dada, fazendo com que uma camada da sociedade permaneça invisibilizada. Neste caso, a população afrodescendente teve negado o direito à inserção na educação, à participação no processo histórico e social da nação. O currículo imposto pelo poder estabelecido soterrou e soterra a verdadeira história das populações vindas da África e de seus descendentes. Os lugares de educação formalizada têm contribuído para a reprodução de uma cultura racista e segregacionista quando desconhece as maneiras corretas de atuar para uma educação antirracista ou quando conhece e não age para a mudança das ações de racismo no seu locus. Pois, durante a maior parte do processo histórico:

Por meio da imposição de modelos culturais europeus, implantou-se no Brasil uma visão de mundo na qual o que era considerado o melhor e o mais correto estaria ligado aos valores europeus e, dessa forma, todos os outros passaram a ser avaliados à luz dos parâmetros da cultura europeia (BUENO, 2008, p. 15).

Diante de tais condições sócio-históricas é que a Lei 10.639/2003 vem institucionalizar o ensino a respeito da História e da Cultura Africana e Afrobrasileira; a mesma modificou a Lei de Diretrizes e Bases da Educação Nacional (LDB) do ano de 1996. Este documento, até então, não trazia a obrigatoriedade, em seu corpo, para discutir as questões voltadas à cultura e história dos (as) negros (as). Durante muitos anos, a história das populações africanas e afrodescendentes ficou à margem dos olhares da humanidade e, quando esta vinha, surgia de maneira distorcida e aviltante.

A história traçada acerca da África, das populações negras, dos afrodescendentes no Brasil e sua participação na sociedade nacional sempre foi descrita por uma perspectiva negativa, muitas vezes invisibilizando a ação dos atores negros e os colocando sempre em situação de subalternidade, assim, interferindo numa real formação identitária que 
pudesse afirmar ter pertencimento nas origens da população negra (GOMES, 1995; LIMA, 2005; MOREIRA; CÂMARA, 2008).

Neste sentido, a pesquisa em questão pretende analisar e discutir questões relacionadas à Lei acima citada, que tornou obrigatório o Estudo da História e Cultura Africana e Afro-brasileira na educação básica no Brasil, e, posteriormente, alterada pela Lei 11.645/2008 que trouxe nova redação à Lei 10.639/2003, inserindo conteúdo da Cultura e da História Indígena Brasileira. Percebe-se que esses temas são poucos discutidos nas escolas, o que preocupa, pois deve ser nesse espaço que deveria cuidar dessas questões tão distintas e importantes na vida dos alunos, da comunidade e da convivência em sociedade como um todo.

A Medida Provisória (MP) 746\2016, ratificada pela Lei 13.415/2017, as quais estabelecem mudanças no Ensino Médio, não estabelece claramente as disposições sobre o Ensino de História e Cultura Africana e Afro-brasileira, podendo futuramente interferir inclusive na formação do ensino fundamental II, já que este é a entrada para o Ensino Médio. Essa mudança sugerida pelo atual governo revela-se como proposta construir um modelo de educação básica voltada à formação técnica em detrimento de uma perspectiva mais humanista, gerando como consequência, maiores dificuldades na implementação do tema.

Esta dificuldade é compreendida quando a Lei 13.415/2017 não traz nenhuma alusão proposta às Leis $10.639 / 2003$ e 11.645/2008. A não abordagem, de forma evidente, na legislação educacional brasileira da importância da História e Cultura Africana e Afro-brasileira e das contribuições da população indígena é fator que pode vir acarretar o não debate na educação básica, uma vez que a lei não exige. O que se propunha na Lei 10.639, o ensino não se torna mais obrigatório dentro das escolas brasileiras gerando uma ação apenas das pessoas e profissionais sensíveis à temática, como já é comum nos dias atuais.

Mesmo com a Lei 10.639/2003 que coloca à obrigatoriedade do Estudo da Cultura Africana e Afro-brasileira no ambiente escolar, é nítida a necessidade de elaborar mudanças não somente por parte do professor,

Revista Exitus, Santarém/PA, Vol. 9, № 5, p. 22 - 46, Edição Especial 2019. 
mais de toda a escola, despertando um grande desafio em estabelecer meios de combate à discriminação e ao racismo. No entanto, percebe-se a necessidade de trabalhar essa temática no ambiente escolar, pois se sabe que é na escola o primeiro passo a ser dado com relação às gerações futuras, pois o papel fundamental dela é trabalhar e educar o futuro da nossa geração.

Assim propomos analisar, juntamente aos professores e alunos, os estudos e as práticas abordadas nas escolas de ensino infantil e fundamental, na cidade de Brejo Santo-CE, acerca da inserção da Lei 10.639/03 e investigar. Objetiva-se investigar a existência e o processo de aplicação dessa lei nas escolas. Especificamente, busca-se: Constituir uma análise de discussão ponderando o nível de conhecimento do corpo técnico e docente, acerca da Lei 10.639/2003; analisar os procedimentos e os métodos adotados pelas escolas públicas municipais, para implementação da legislação em questão; investigar a prática docente no tocante as dificuldades na aplicação da lei.

\section{APORTE TEÓRICO: PRELAÇÕES GERAIS}

A Lei 10.639 aspira fortalecer a identidade racial no Brasil e mesmo tornando obrigatório o Ensino de Culturas e Histórias Afro-brasileiras ainda é nítida dentro das escolas, a discriminação racial contra população negra, fato gerador de consequências para crianças, sejam elas negras e/ou brancas, as quais reproduzem o racismo que fere a humanidade, causando problemas psicológicos, autoestima, etc. (CAVALLEIRO, 2005). Deve-se buscar elaborar nas escolas identidades que reflita uma sociedade não racista, uma organização social de combate a toda e qualquer tipo de preconceito. As ações educativas nas escolas devem elaborar práticas individuais e coletivas que fortaleçam as identidades antes negadas no processo educacional eurocentrado, em que nega a participação e as contribuições das populações africanas, de seus descendentes e também dos indígenas brasileiros. O sentimento de identidade não deve negar esses grupos, mas reconhecê-los, e somente será possível a partir de uma prática 
democrática e de respeito à diversidade; assim o Sentimento de Identidade pode ser resgatado e afirmado. Entretanto, de forma contrária, pode haver o apagamento das memórias e, por conseguinte, a negação de outras histórias que estão fora das relações de poderes, assim o apagamento de identidade e/ou identidades.

Memórias são mitigadas e histórias são negadas na medida em que não se guarda partes das histórias, porque não pertencem às histórias das grandes representações e símbolos nacionais, numa perspectiva positivista. Nas escolas e em suas praticas educativas não são diferentes. Predomina a história dos "grandes vultos", ficando às margens a participação de negros/as e dos "índios/as". Com a destruição dos lugares de memória, a história dita oficial, nega a presença negra e, consequentemente, esta não se fará presente na parte de conteúdos curriculares importantes a serem estudados, os estudos sobre a cultura e a história da população africana, afro-brasileira e indígena são negadas (DOMINGOS, 2015).

Nesse sentido, existe um consenso em que afirma a necessidade de procurarmos estudar o que propõe a Lei 10.639/2003 e as Diretrizes Curriculares Nacionais para os Estudos das Relações Etnico-Raciais e para o ensino da História e Cultura Africana e Afro-Brasileira (2004), no intuito de buscar se construir as identidades antes negadas, sejam estas individuais ou coletivas; a retomada das "boas lembranças" (a recuperação positiva das contribuições de africanos e de seus descendentes) seria o ponto marcador que determinaria a identidade e a autoestima da população negra brasileira, nas escolas de educação básica. O relembrar seria fator de identificação com a comunidade da qual faz ou fez parte. Os fatos presentificados, a transmissão das experiências vividas, os símbolos mantidos são perpetuados em função da ação realizada pela memória, pela retomada da memória, pela recuperação da história e da cultura descolonizada. Somente pela memória e pela recuperação desta história descolonizada pode se ter outra visão de mundo africano e afrodescendente. Eventos pelos quais, se faz continuar as identidades e 
relações sociais, neste caso, visando uma construção identitária positiva e que permita autoestima a população negra (DOMINGOS, 2015).

Nesse sentido, o estudo sobre as africanidades e suas contribuições à sociedade brasileira, tem por função refazer e reatualizar o sentido de pertencimento de um povo em contraposição ao poder de diluição que o tempo possui. A extinção da memória coletiva coloca em xeque identidades de sociedades, eliminando possibilidades de existência, isto é, "a falta ou a perda, voluntária ou involuntária, da Memória Coletiva nos povos e nas nações [...] pode determinar perturbações graves da Identidade Coletiva" (LE GOFF, 1996, p. 425).

Portanto, deve-se considerar que a escola tem a função de recuperar as memórias históricas antes esquecidas de africanos e de seus descendentes, pois esses fatos passados permitem perpetuar as identidades de um grupo. As memórias históricas, recuperadas e reelaboradas contribuem para a boa funcionalidade do fazer educacional e, consequentemente, para a construção da autoestima e autoafirmação das identidades negras antes maginalizadas. O espaço da escola pode ser lugar para se refazer vidas esquecidas, legitimar existências de fatos, imprimir sentimentos de pertencimentos, capazes de se manter frente às intempéries do tempo e das ações de racismo e de preconceitos contra a população negra. Os ensinamentos continuam e mantêm existências de povos. Enfim, a escola junto ao ato de educar para a diversidade e o respeito às diferenças eternizará a existência de grupos, assim, permitindo a manutenção da história, da cultura e da identidade (DOMNGOS, 2011; DOMINGOS, 2015).

Nesse sentido, a formação adequada do educador é de fundamental importância para que a implementação e abordagem do que trás a Lei 10.639, pois é de grande relevância neste processo socioeducativo a atuação do professor. Nesse contexto, percebe-se que a participação de todos, que de forma direta ou indireta estão inseridos no ambiente escolar, se façam presentes no combate ao racismo e outros tipos de preconceitos. Pois, 
Na sala de aula, a condição do professor de estar alheio perante as questões étnicas raciais, aumenta e compactua com o preconceito, principalmente quando analisamos o livro didático que não contempla a valorização da história do legado africano. Faz-se necessário que o professor na sua prática docente institua em suas aulas uma imagem positiva da cultura africana, contribuindo para o desenvolvimento e formação de uma identidade negra positiva no cotidiano escolar, o que implica em formação contínua que o prepare para lidar com a discussão em sala de aula (DOMINGOS, SANTOS, 2005, p. 298-299).

Tendo em vista o debate entre os educadores para a disseminação de novas ideologias, para obter novos métodos de se trabalhar a temática, estas trocas de ideias e exposição de argumentos também poderiam ser abordadas, para que se pudesse repensar e buscar mudanças nos materiais que, na maioria das vezes, não dão ênfase às contribuições da população negra à história da formação da sociedade e cultura brasileira.

Dentro do processo histórico do desenvolvimento e distribuição da educação brasileira, em sua maior parte os/as negros/as foram onerados, fato originário no período colonial, uma educação racista, desigual de desfavorecimentos à população afro-brasileira e aos africanos. Fatores que continuam trazendo consequências negativas à população afro-brasileira nas escolas, episódio perceptível quando se busca compreender a relação entre a presença desse grupo social e o espaço escolar ou entender a prática educativa de combate ao racismo, são ações que pouco existem. Nas investigações, o ambiente escolar acaba sendo também um ambiente de reproduzem do racismo. Portanto,

[...] a escola é um espaço privilegiado na promoção de uma educação antirracista, principalmente pela diversidade de pensamentos e por ser um local socializador de conhecimentos. [...] quando se fala em discriminação racial na escola, isso não significa dizer que a partir de agora a escola vai propor estratégias para a criança negra [adolescentes e jovens ${ }^{4}$ ] enfrentar o preconceito, até porque isso não é um problema apenas da criança que é negra, implica dizer que, trazer o debate das relações étnico-raciais para a sala de aula é uma oportunidade de crianças negras e não negras se conhecerem, discutirem e socializarem novas formas de relacionamentos, que tenham impacto em suas vidas e na sociedade como um todo (DOMINGOS; SANTOS, 2005, p. 300).

\footnotetext{
${ }^{4}$ Grifo nosso
} 
Diante do que foi pautado é nítido que o a educação brasileira precisa de avanços e melhorias no que diz respeito à população afrodescendente, na busca de garantir uma educação sem discriminação, de respeito aos direitos, à igualdade no âmbito educacional, tornaram-se urgente a valorização da diversidade cultural e étnico-racial. É preciso "garantir o exercício desse direito e forjar um novo modo de desenvolvimento com inclusão é um desafio que impõe ao campo da educação decisões inovadoras [...] valorizando a riqueza de nossa diversidade étnico-racial e cultural" (BRASIL MEC, 2004 p. 05).

No processo de uma distribuição igualitária, de forma que preserve a perspectiva da diferença que possa atender a todas as classes e raças da sociedade, se faz necessária, a mobilização de toda a população (BRASIL, MEC, 2004). O processo de democratização e igualdade ao acesso à educação, ao estudo da temática que possa revelar a influência da população negra e africana na sociedade brasileira, é tida como algo promissor, no que diz respeito à formação de uma sociedade mais justa e menos preconceituosa. Na história da educação brasileira foram sendo pautadas e feitas mudanças, embora nos dias atuais ainda se registre falhas e muitas vezes atividades não são realizadas, para que se tenha uma educação menos centralizada em uma única raça, e que se possa com maior frequência trazer à importância da cultura africana a educação nacional (GOMES, 2008; MUNANDA; GOMES, 2004).

Assim, é de grande relevância pensar uma prática educativa inclusiva na escola que garanta a efetivação da cidadania, logo, legitimando a igualdade de direitos refletida na alteridade. Esse modelo de ser cidadão que dá base para uma ação transformadora foi negada aos negros/as, grupos sociais marcados por discriminações raciais e pela exclusão social. Logo, tanto a forma cidadã de ser e a educação para a população negra tem sido subtraída por um grupo dominante e racista que controla as relações de poderes. O modelo hegemônico racista está, simbolicamente, representado nos espaços educativos institucionalizados. Esse molde permite 
a perpetuação do poder de uma elite branca contrária à cidadania da população afrodescendente (CUNHA Jr., 2007; MUNANGA; GOMES, 2004).

A tarefa da educação para igualdade racial é a de reconstruir a estrutura dada, de forma crítica e transformadora, que sempre esteve atrofiada, pelas palavras do poder hegemônico eurocêntrico. A educação tem o dever de emergir a história não contada, para que as populações marginalizadas tenham $\circ$ direito de serem conhecidas. Durante muitos séculos a história e a cultura africana e afrodescendente foram escritas e reescritas pelo olhar do outro, assim, tornando-as, a partir da concepção alheia, história "primitiva" e culturas "selvagens" (DCN, 2004; MUNANGA, 2003).

Nessa concepção de transformação social pelo ato de educar, não são possíveis nem desejáveis discursos fechados, homogêneos, hegemônicos, pois a licitude dessa forma de educação deverá ser edificada, sobretudo, pela ação discursiva dos agentes sociais que se localizam as margens das relações sociais dominantes. Pois:

O papel da educação é o de propor elemento para que homem, ao invés de subordinar-se, seja estimulado a ingressar nesse mundo inovado, redefinido-o e aos seus papéis; criticando não apenas os seus valores, mas também, os novos valores introduzidos (BRANDÃO, 1984, p. 53)

Esse pensamento crítico acerca do pensamento hegemônico social brasileiro tenta reorganizar a realidade no intuito de torná-la mais libertadora e equitativa em termos étnicorraciais. O pensamento crítico, construído por sujeitos históricos, permitirá, de forma consistente, descobrir respostas aos problemas e as indagações que estão expostas na estrutura vigente (BRANDÃO, 1984; DOMINGOS, 2015). Portando, "faz-se de indubitável importância o cultivo dos diálogos e das relações práticas da ordem social de maneira a se justaporem no intuito de mutuamente transformar a realidade díspare existente" (DOMINGOS, 2015, p. 59). 
Educação para libertação e o, consequente, pensamento crítico transformador chega ao seu ápice quando sobrepuja as estruturas díspares dominantes, quando supera os preconceitos e as interpretações de mundo que imperaram na atualidade dissonante. Interpretações essas as quais aviltam outros grupos fora do modelo ou dos padrões hegemônicos socialmente preestabelecidos. A educação de cunho libertador não foge da sua essência estratégica de politização, parte inerente da constituição das relações democráticas (GONÇALVES, 1998; SOUSA, 1998; DOMINGOS, 2015).

A tarefa da educação para igualdade racial é a de reconstruir, restaurar, renovar e revigorar a estrutura dada, de forma crítica e transformadora, que sempre esteve atrofiada pelas palavras do poder hegemônico eurocêntrico. A educação tem o dever de emergir a história não contada para que as populações marginalizadas tenham o direito de serem conhecidas. Durante muitos séculos, a história e a cultura africana e afrodescendente foram escritas e reescritas pelo olhar do outro, assim, tornando-as, a partir da concepção alheia, história "primitiva" e culturas "selvagens" (DCN, 2004; MUNANGA, 2003; DOMINGOS, 2015).

Porquanto, compreende-se que a educação deve estar ligada a transformar as relações sociais e humanizar, ou seja, reelaborar o mundo mais igualitário no que se refere às questões raciais, sociais, culturais e políticas. Elaborar e, por conseguinte colocar em prática, um modelo educacional que combata essa estrutura obsoleta que ainda manifesta racismo contra a população negra. Modelo antigo de educação, que manifesta racismo no seu cotidiano reproduzindo-o no seu currículo escolar e no seu material didático (DOMINGOS, 2015).

A educação formal, informal e não formal 5 precisam ponderar e levar em consideração no seu processo educativo que o negro deve ser

\footnotetext{
5 Para maior compreensão dos conceitos de educação formal, informal e não formal ver: LIBÂNEO, José Carlos. Pedagogia e pedagogos, para quê? 5 ed., São Paulo: Cortez, 2002. DOMINGOS, Reginaldo Ferreira. Pedagogias da transmissão da religiosidade africana na casa de Candomblé Yabasé de Xangô e Oxum em Juazeiro do Norte - Ce. Dissertação
} 
localizado na história local, e compreendido em sua forma de ser e agir na sociedade. A educação realizada deve desempenhar a função de inclusão social e compreensão real da realidade dentro de suas diferenças, respeitar o diferente em suas práticas sociais, culturais e religiosas, sem sofrer atos discriminatórios. A educação inclusiva deve estar atenta à inserção de segmentos sociais colocados pelo processo histórico, às margens da sociedade. As práticas educativas no seu fazer pedagógico no dia a dia devem tornar em ato o seu potencial transformador da realidade díspare (DOMINGOS, 2015).

A educação libertadora, como expunha Freire (1987), é direcionada aos sujeitos no sentido de retornar para estes em forma de libertação e conscientização da estrutura segregacionista preestabelecida. Assim, esse processo educacional, funciona com a intenção de tornar os atores realmente humanos e dotados de direito, legitimado e efetivado, pela própria ação do ator transformador que após dominar o poder da fala atua no processo de mudança da realidade. A finalidade dessa educação é uma sociedade justa e equitativa, com direito à participação de deliberação acerca da própria existência e sobre o futuro da sociedade a qual está inserido (FREIRE, 1987; DOMINGOS, 2015).

\section{O LOCUS DA PESQUISA E O MÉTODO: AS PRIMEIRAS EMPREITADAS E RESULTADOS PARCIAIS}

A pesquisa apresentada nessas considerações está direcionada a treze escolas da rede pública municipal de uma cidade do interior cearense, sendo cinco escolas de Educação Infantil e oito de Ensino Fundamental, localizadas na Zona Urbana, da cidade de Brejo Santo - CE. Tal delimitação se deu por duas razões: a primeira pela complexidade de grande parte dessas escolas estarem sediadas na Zona Rural do município; e segunda, pelo método que visa observação, entrevistas e estudos de documentos que demandará muito tempo em campo. 
Os primeiros passos da pesquisa foram a partir de estudos teóricos, centrados, inicialmente, nas legislações, estudo sobre a análise da formação do currículo escolar para o trabalho do multiculturalismo nas escolas, das questões étnico-raciais, bem como as diretrizes que tratam o tema. Referenciais bibliográficos de outras pesquisas, também já se encontram catalogados e em fase inicial de estudos como base teórica aos alunos/as bolsistas. Neste arrolamento, pretendeu-se estudar História da Educação Brasileira, em seguida, buscar pesquisas realizadas no Brasil acerca das práticas docentes, nas escolas de educação fundamental, voltadas a aplicação da Lei 10.639/2003 e sobre o currículo, este como ferramenta determinante na construção e manutenção de um poder simbólico nas instituições escolares. Tal caminho se justificou pelo fato de permitir uma aproximação com o objeto da pesquisa e/ou da temática e, segundo, as revisões bibliográficas ajudam a "entrelaçar" os pensamentos e a fundamentar as informações coletadas empiricamente, sejam documentos ou falas de agentes sociais.

O momento seguinte foi e continua sendo a observação, simultaneamente com as entrevistas, que pretende estudar o ambiente para compreender a realidade, as instalações, organização, decorações, cartazes expostos nas paredes das escolas, a prática do corpo técnico e do núcleo gestor e, por fim, a ação docente no seu ato de ministrar aula. O ato de observar é importante porque tem como ação principal aproximar o sujeito pesquisador do locus da pesquisa, permite um contato inicial e compreender a ambiência. O pesquisador ao observar o lugar de estudo estará provido dos referenciais teóricos que o subsidiará a entender a importância de examinar esses espaços e a disposição organizacional dos mesmos (MINAYO, 1994; LÜDKE, ANDRÉ, 1986; ECO, 2002).

No presente momento, a investigação encontra-se na fase das entrevistas e/ou questionários semiestruturadas que possibilitarão, a priori, direcionados a obter as respostas para a problemática colocada na proposta investigativa. Entende-se, portanto, que os questionamentos elaborados não são "camisas de força" engessadas, as quais não possam

Revista Exitus, Santarém/PA, Vol. 9, № 5, p. 22 - 46, Edição Especial 2019. 
ser redirecionadas no momento da aplicação. Elaborar perguntas antecipadamente, não significa dizer que teremos em campo, a real possibilidade de pô-las em prática, como está sendo experienciado no presente no momento de aplicação. Embora, compreenda-se serem relevantes questionamentos, previamente elaborados, porque nos permitem buscar, antecipar e alcançar respostas o mais próximo possível das hipóteses levantadas. As entrevistas coletadas serão catalogadas e transcritas no intuito de compreender, como se nota na pesquisa qualitativa, a dimensão simbólica e os significados humanos na prática da inserção da Lei 10.639/2003 nas escolas em estudo.

O quarto momento da empreitada investigativa serão estudos de documentos, Projetos Políticos Pedagógicos (PPPs) ou outros registros que comprovem práticas docentes na aplicação da lei serão outras fontes na busca de respostas. As inquirições sobre os documentos pretendem-se problematizá-los para entender que o registro do mesmo foi realizado dentro de um contexto conjunturalmente determinado. Neste tipo de análise recorrer-se-á ao olhar sociológico e histórico, pois, acredita-se que tal percepção epistemológica dará habilidade para que se possa verificar, de forma crítica, a documentação. Nesses documentos busca-se vestígios que levem a encontrar propostas de implementação da lei ou detectar possíveis ações anteriores realizadas nas escolas investigadas.

Inicialmente, podemos edificar, com base nas investigações bibliográficas e o contato feito a partir da observação inicial no ambiente, já que a pesquisa está em fase inicial, alguns resultados e discussões. Através da pesquisa poder-se-á conhecer as escolas, suas ações de ensino, como atuam no intuito de colaborar na formação do pensamento crítico-reflexivo, quais métodos de ensino adotados no combate à cultura racista, as formas de ações para a implantação da História e Cultura da População Africana e Afrodescendente, a realização de atividades de superação a lógica excludente e preconceituosa. Como as escolas buscam resistir à homogeneização da cultura hegemônica excludente. Dessa forma, perceber a necessidade de fazer a investigação no intuito de compreender, 
a partir de referenciais bibliográficos e da pesquisa em campo, o processo de implementação da Lei 10.639/2003 nas escolas. Detectar as formas de trabalhos adotadas nas escolas e, posteriormente, criar meios para aperfeiçoamento de implementação da lei em questão.

Aparado em estudos em outros âmbitos universitários e observações constata-se que existe falhas na aplicação do que se pretende a lei aqui em questão. Mantém-se, na maior parte das escolas visitadas, a prática de realizar apenas duas atividades anuais, uma em 13 de maio e outra em 20 de novembro, esta em comemoração ao dia da Consciência Negra, morte de Zumbi dos Palmares, aquela se referindo a Abolição da Escravatura. Os referenciais estudados esclarecem que trabalhar apenas duas vezes ao ano uma temática tão ampla e complexa não é suficiente e deixa muito a desejar. Os estudos ainda demostram que se faz necessário criar métodos e técnicas de formação continuadas para que professores possam trabalhar de forma adequada os conteúdos e não sair reproduzindo uma história de perspectiva eurocêntrica (CAVALLEIRO, 2001; CAVALLEIRO, 2003).

Amparados na ferramenta de observação já se pode inferir algumas reflexões, pois disposição do ambiente ajuda a compreender, com as devidas proporções, as estruturas organizacional e ideológica do espaço escolar, como se observa nas imagens abaixo registradas em escolas pesquisadas:

\section{FIGURA 1}

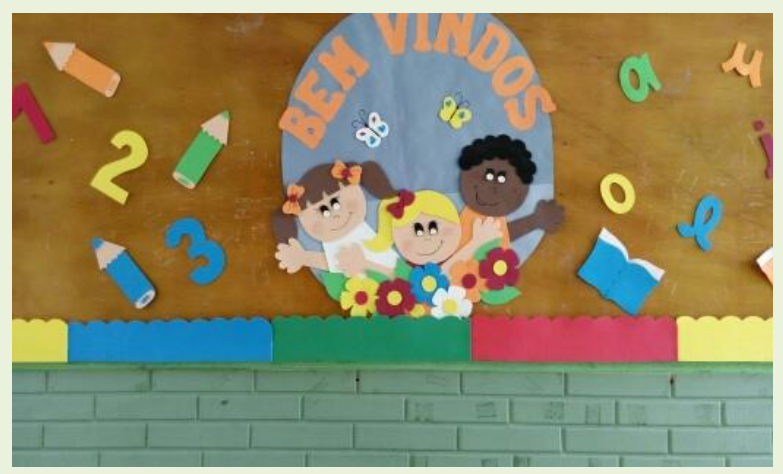

Fonte: Reginaldo Domingos 
Imagens presentes no acesso central da escola em que nos revela que mesmo sem o devido conhecimento acerca da Lei 10.639/2003 existe uma ação de inclusão da imagem de afro-brasileiro no espaço escolar. Importante destacar que o registro acima é fruto de atividades de conscientização para uma educação de respeito à diversidade, mas, que ainda se mantêm restritas a dois momentos anuais, já citadas na nossa análise, 13 de maio e 20 de novembro. Outra escola afirma que se discute a temática, porém, de forma mais profunda e densa somente no mês de novembro. São afirmativas de profissionais desses espaços. É de grande importância destacar que essas atividades são de grande relevância no processo de reconhecimento da história, da cultura, das contribuições de africanos e afrodescendentes e para a construção da identidade negra brasileira, mas que não pode se restringir apenas a datas esporádicas.

Em uma terceira escola registrou-se a imagem abaixo:

\section{FIGURA 2}

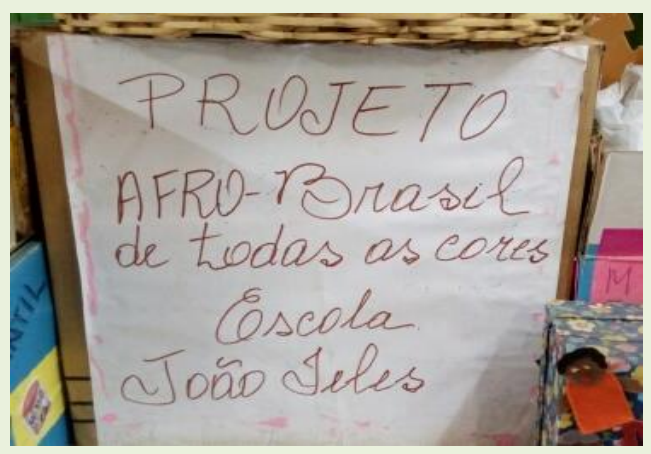

Fonte: Reginaldo Domingos

Na imagem acima capturada na biblioteca de outra escola, em uma visita no mês de novembro do ano de 2017. Nesta, a diretora também desconhecia a lei e seu conteúdo, embora realizasse trabalho voltada a temática africana, afro-brasileira e atividades voltadas ao combate ao racismo, durante todo 0 ano letivo. Embora as atividades, fossem trabalhadas com mais intensidade no mês de novembro, conhecido como o mês da Consciência Negra, neste são realizadas fastígios com exposições de projetos expondo as culturas africanas. Diferente das anteriores duas 
anteriores, esta tem a preocupação de trabalhar durante todo o ano letivo, não obstante, o ápice do momento reflexivo de toda a comunidade escolar ocorre apenas no mês de novembro.

É relevante compreender que durante décadas a história das populações africanas e afrodescendentes ficou marginalizada aos olhares da humanidade, às vezes que emergia era de maneira distorcida e aviltante. A história sobre a África, africanos e afrodescendentes, sua participação na sociedade nacional foram descritas por uma perspectiva negativa, muitas vezes invisibilizando a ação desses atores sociais e os colocando sempre em situação de subalternidade, assim interferindo na formação identitária da população afrodescendente (GOMES, 1995; LIMA, 2005; MOREIRA; CÂMARA, 2008).

Dessa maneira, sendo o reconhecimento da história e cultura afrobrasileira, bem como o campo da literatura, de importância fundamental no desenvolvimento humano, cabe à escola promover acessos a diferentes fontes e perspectivas que agreguem tanto uma como a outra. Nas escolas de ensino infantil, as quais fazem parte do campo investigativo, tem-se trabalhado alguns livros de histórias infantis, no intuito de discutir a temática. Pode-se observar o uso de atividades realizadas como Menina Bonita do laço de fita de Ana Maria Machado; Princesa Arabela mimada que só ela de Mylo Freeman, tradução de Ruth Salles; Bruna e a galinha d' Angola de Gercilda de Almeida; Os cabelos de Lelê de Valéria de Belém, fazendo compreender que de alguma forma as escolas buscam trabalhar 0 conteúdo. Conforme se observa nas imagens que seguem abaixo:

FIGURA 3: Os cabelos de Lelê de Valéria de Belém

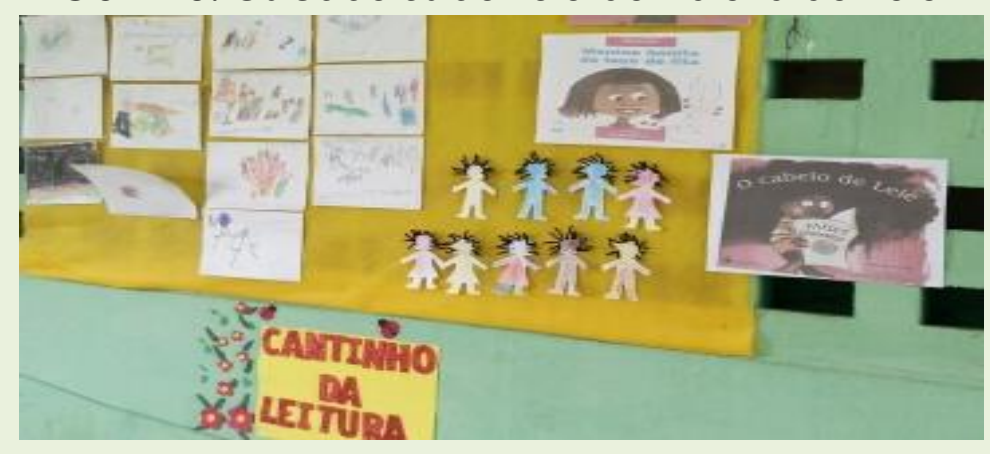

Fonte: Reginaldo Domingos

Revista Exitus, Santarém/PA, Vol. 9, № 5, p. 22 - 46, Edição Especial 2019. 
FIGURA 3: Bruna e a galinha d' Angola de Gercilda de Almeida

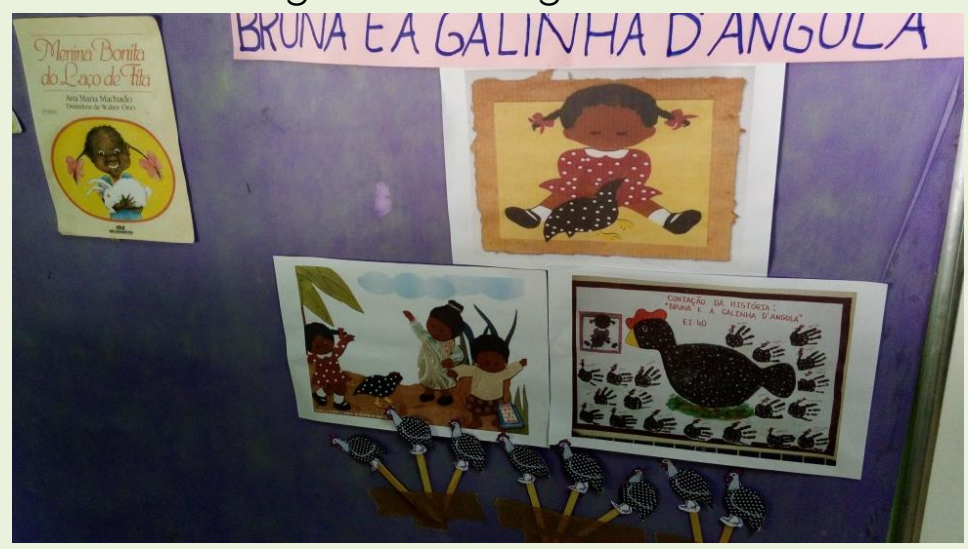

Fonte: Reginaldo Domingos

Nessa perspectiva, é importante salientar que a pesquisa proposta se encontra em andamento, mas que nas inquirições iniciais, pode-se observar o ambiente e sua organização quando analisado, a reprodução imagética vê-se uma equidistância entre imagens que reproduzem predominância de imagens do mesmo, no intuito de compreender a dinâmica. Nessa analise, entende-se que o uso de imagens positivas é de grande relevância para a formação da identidade da criança e/ou adolescente e/ou jovem negro/a. E as histórias, acima citadas, trabalhadas pelas escolas em muito contribuirão para essa formação identitária.

fato de o educador estar alheio diante as questões étnico-raciais, pode contribuir para a perpetuação do racismo contra a população negra quando o livro didático não valoriza a história e cultura da população africana e afrodescendente. Portanto,

\footnotetext{
Faz-se necessário que o professor na sua prática docente institua em suas aulas uma imagem positiva da cultura africana, contribuindo para o desenvolvimento e formação de uma identidade negra positiva no cotidiano escolar, o que implica em formação contínua que o prepare para lidar com a discussão em sala de aula (DOMINGOS; SANTOS, 2005, p. 298-299).
}

Destarte, a instituição escolar é o locus que deve privilegiar a promoção de uma educação antirracista, a diversidade de pensamentos e de relações sociais pela sua função de construção de saber crítico reflexivo. Importante destacar que a escola ao tratar de discriminação racial se 
propõe a realizar estratégias, tanto para a criança negra enfrentar o preconceito que recai sobre si, quanto para que crianças brancas entendam sua responsabilidade para com o outro, para a diferença, o respeito à diversidade; entender que o outro faz parte de sua existência. Uma vez que, não é "um problema apenas da criança que é negra [...] o debate das relações étnico-raciais para a sala de aula é uma oportunidade de crianças negras e não negras se conhecerem, discutirem e socializarem novas formas de relacionamentos, que tenham impacto em suas vidas e na sociedade como um todo" (DOMINGOS; SANTOS, 2005, p. 300).

É de grande relevância demonstrar como a criança apreende informações e elabora conhecimento de mundo e de si mesmo com uso e leitura de imagens, especialmente, crianças em fase de alfabetização, pois as imagens são base, nesta fase escolar, para a compreensão de mundo. Neste sentido, devem-se avaliar estórias infantis e as personalidades presentes nelas e que, por conseguinte, estão presentes no mundo e perpetuarão no imaginário infanto-juvenil, pois, tem-se notado que a realidade desse grupo está muito ligada a esse universo imaginário e, que muitas vezes, não tem favorecido para um reconhecimento de uma identidade negra e afrodescendente, pois o mundo e o modelo dado como perfeito e belo tem se perpetuado o eurocentrado. Neste sentido, as crianças afrodescendentes não se identificam como negras ou com sua cultura, "mesmo tendo marcado em sua pele, no seu cabelo, nos seus ancestrais, nas características da sua negritude", (DOMINGOS, SANTOS, 2005, p. 304) as africanidades, sua herança vinda do além-atlântico.

\section{"IN/EN" CONCLUSÃO: CAMINHOS PARA UMA REFLEXÃO}

Ao tratarmos da História e Cultura Africana e Afro-Brasileira no âmbito educacional, contribuímos com as devidas proporções, para a construção de práticas educativas e de caráter cultural e histórico no contexto escolar, partindo de conceitos chaves como identidade, diferença e alteridade. Ao trazer essa temática para discurso escolar, acredita-se permitir novas aberturas de práticas educativas, como a interdisciplinaridade, 
multidisciplinaridade, criando ações pedagógicas e educativas na promoção para a diminuição das desigualdades de raças e atos de racismo contra a população negra brasileira.

Tais atitudes possibilitam busca de autonomia daquele que educa e do educando, autorreconhecimento de ambas as partes, valorização do que somos, e por fim, a construção de uma consciência histórica, pois ainda é muito comum encontrar educadores e educandos terem suas raízes culturais africanos e afro-brasileiros, seus pertencimentos de ascendência racial afrodescendente, porém, não os notando. Sempre colocando a cultura como sendo do outro e não sua, outras vezes, a herança racial como sendo aquela e não esta, nossa.

O envolvimento da Cultura Africana e Afro-brasileira não está apenas em dar visibilidade no âmbito escolar, é preciso também, adotar medidas que tragam melhor embasamento e conhecimento para todos, na questão de inclusão e respeito à diferença, porém, para isso se tornar visível, a escola juntamente com a sociedade tem o dever de aderir a propostas, nas quais teoria e a prática andem lado a lado, trabalhando também a questão do preconceito/racismo e todo e qualquer tipo de desigualdade entre raças, dentre outras questões que progridem até os dias atuais. Partindo dessas considerações, é evidente destacar a importância da escola e do professor, não apenas pelo simples fato de ensinar, mas perceber que acima disso, está no seu dever educar para liberdade, respeito à diversidade e inclusão.

As primeiras conclusões que se pode inferir, a partir de estudos bibliográficos e de documentos oficiais é que, levar às escolas o debate acerca da História Africana e a Cultura Afro-brasileira é de grande relevância quando se trata de construir uma identidade positiva que permita a população afro-brasileira elevar sua autoestima. Conhecer o legado cultural, político e social perpetuados pelo povo africano é fundamental nesse processo de edificação identitária não eurocentrada.

No tocante às escolas de ensino infantil e fundamental da cidade, foco investigativo, constatou-se a existência de atividades realizadas no intuito de discutir a temática África e africanidades, mesmo que nesses casos

Revista Exitus, Santarém/PA, Vol. 9, № 5, p. 22 - 46, Edição Especial 2019. 
o núcleo gestor escolar desconheça a Lei 10.639/2003, seu conteúdo e as diretrizes que a orienta. Nesse contexto, percebe-se que é de fundamental importância, o corpo gestor e docente procurar meios e métodos para que possam trabalhar com seus alunos de forma interdisciplinar, a prática educativa, voltada ao fortalecimento da implementação da legislação em questão. É relevante destacar que apesar das mudanças e dificuldades apresentada nas últimas décadas e com a conjuntura política e educacional, manter e refletir sobre diversidade, democracia e equidade, tomando como ponto de partida, neste caso especifico, a cosmovisão africana, pois entende-se que é indispensável no crescimento de uma sociedade mais justa, mais igualitária, menos racista, menos preconceituosa.

\section{REFERÊNCIAS}

BRASIL, MEC. Diretrizes Curriculares Nacionais para Educação das Relações Étnico-raciais e para o Ensino de História e Cultura Afro-Brasileira e Africana. Brasilia. 2004.

BRASIL. Diretrizes Curriculares Nacionais para a Educação das relações Étnico-Raciais e para o Ensino de História e Cultura Afro-brasileira e Africana. Ministério da Educação. Brasília, julho de 2004.

BRASIL. LEI No 13.415, DE 16 DE FEVEREIRO DE 2017. Disponível em < http://www.planalto.gov.br/ccivil_03/_ato2015-2018/2017/lei/L13415.htm>. Acesso em: 29/09/2017.

BRASIL. Medida provisória. N 746, DE 22 DE SETEMBRO DE 2016. Disponível em < http://www.planalto.gov.br/ccivil_03/_ato2015-

2018/2016/Mpv/mpv746.htm>. Acesso em: 29/09/2017.

BRASIL. Presidência da República. Casa Civil. Lei no 10.639. Publicada em 09 de janeiro de 2003. Disponível em

<http://www.planalto.gov.br/ccivil_03/leis/2003/L10.639.htm>. Acesso em: $29 / 09 / 17$.

BRASIL. Presidência da República. Casa Civil. Lei no 11.645. Publicada em 09 de janeiro de 2003.Disponível em:

<http://www.planalto.gov.br/ccivil_03/_ato2007010/2008/lei/l11645.htm>. Acesso em: 29/09/17. 
CUNHA Jr., H. Os negros não deixaram escravizar: temas para as aulas de história dos afrodescendentes. Revista Espaço Acadêmico. № 69, Ano VI, fevereiro, 2007.

DOMINGOS, R. F. Religiões tradicionais de base africana no cariri cearense: educação, filosofia e movimento social. 2015. Tese (Doutorado em Educação) - Universidade Federal do Ceará, Fortaleza/Ce, 2015.

DOMINGOS, R. F.; SANTOS, A. P. dos. Contando e recontando a África, jeitos de sentir as raízes afro-brasileiras no $2^{\circ}$ ano do ensino fundamental: uma proposta de ensino para a lei 10.639/2003. Revista da ABPN, v. 7, n. 16 - mar jun., p.294-317, 2015.

DOMINGOS, R. F.; OLIVEIRA, A. F. B. de. Literatura infantil: uma proposta educativa para a valorização das africanidades e afrodescendências numa perspectiva multi e interdisciplinar. Revista fórum identidades, Itabaiana-SE, Universidade Federal de Sergipe, v. 25, p. 143-160, set.-dez. 2017.

RIBEIRO, R. S. F. A saúde mental do trabalhador e a educação como forma de cuidado. In: SIMPOSIO DO LAGE, 7., 2009, Campinas. Anais... Campinas: Universidade Estadual de Campinas, 2009. p. 73-80.

CAVALLEIRO, E. dos S. Do silêncio do lar ao silêncio escolar: racismo, preconceito e discriminação na educação infantil. São Paulo: Contexto, 2003.

CAVALLEIRO (org.). Racismo e Anti-Racismo na Educação: repensando nossa escola. São Paulo: Selo Negro, 2001.

DEMO, P. Pesquisa: princípio científico e educativo. 12 ed. São Paulo: Cortez, 2006.

DOMINGOS, R. F. Pedagogia da Transmissão na Religiosidade Tradicional de Base Africana: um estudo histórico e filosófico em Juazeiro do Norte - CE. Jundiaí: Paco, 2015.

ECO, U. Como se faz uma tese. 19 ed. São Paulo, Perspectiva, 2002.

FREIRE, P. Pedagogia do oprimido. $17^{a}$ ed. Rio de Janeiro: Paz e Terra, 1987.

GOMES, N. L. A mulher negra que vi de perto. Belo Horizonte: Mazza Edições, 1995.

LE GOFF, J. História e Memória. 4. ed. Campina: UNICAMP, 1996.

LÜDKE, M.; ANDRÉ, M. E. D. A. Pesquisa em educação: abordagens qualitativas. São Paulo: EPU, 1986. 
MUNANGA, K.; GOMES, N. L. Para entender o negro no Brasil de hoje: história, realidades, problemas e caminhos. São Paulo: Global, Ação Educativa Assessoria, Pesquisa e Informação, 2004. (Coleção Viver, Aprender).

MINAYO, M. C. de S. (org.). Pesquisa social: teoria, método e criatividade. Petrópolis: RJ: Vozes, 1994.

NUNES, C. (Org.). Artefatos da Cultura Negra no Ceará. Fortaleza: Edições UFC, 2011.

BUENO, M. N. N. O samba: cantando a História do Brasil. In: RASSI, Taleb (Org). Negros na sociedade e na cultura brasileiras III. Goiânia: Ed. da UCG, 2008. p. 15-32.

CAVALLEIRO, E. dos S. Discriminação racial e pluralismo em escolas públicas da cidade de São Paulo. IN: SECAD, 2005, pp, 65-104.

CUNHA Jr. H. Cultura Afrocearense. In. CUNHA Jr., Henrique; SILVA, Joselina e NUNES, Cícera (Org.). Artefatos da Cultura Negra no Ceará. Fortaleza: Edições UFC, 2011.

FILGUEIRA, A. L. de S. Inserção social do negro no Brasil: uma análise a partir do pensamento de Hannah Arendt. In: RASSI, T. Negros na sociedade e na cultura brasileiras III. Goiânia: Ed da UCG, 2008.

GOMES, A. B. S. O movimento negro e a educação escolar: estratégias de Iuta contra o racismo. In: GOMES, A. B. S.; CUNHA Jr.; H. (Org.). Educação e Afrodescendência no Brasil. Fortaleza: Edições UFC, 2008. p. 15-32.

GONÇALVES, E. P. Educação popular: entre a modernidade e a pósmodernidade. In: COSTA, M. V. Educação popular hoje. São Paulo: Loyola, 1998. p. 213-230.

LIMA, H. P. Personagens negros: um breve perfil na literatura infanto-juvenil. In: MUNANGA, K. Superando o racismo na escola. Brasília: Mec/secad, 2005. p. 101-116.

MOREIRA, A. F. B.; CÂMARA, M. J. Reflexões sobre currículo e identidade: implicações para a prática pedagógica. In: MOREIRA, A. F.; CANDAU, V. M. (org). Multiculturalismo: diferenças culturais e práticas pedagógicas. Petrópolis: RJ, Vozes, 2008. p. 38-66.

MUNANGA. Políticas de ação afirmativa em beneficio da população negra do Brasil: um ponto de vista em defesa de cotas. In: GONÇALVES e SILVA, P. B.; SILVÉRIO, V. R. (Ogr.). Educação e ações afirmativas: entre injustiças simbólicas e a injustiça econômica. Brasilia: INEP, 2003. p. 115-128. 
ROCHA, L. C. A formação de educadores (as) na perspectiva étnico racial na rede municipal de ensino de São Paulo (2001-2004). IN: ROMÃO, J. (Org.). História da educação do negro e outras Histórias. Brasília: SECAD/MEC, 2005. p. 201-218.

SOUSA, J. F. Educação popular para o terceiro milênio: desafios e perspectivas. In: COSTA, M. V. (Org.). Educação popular hoje. São Paulo: Loyola, 1998. p. 11-30.

Recebido em: 26 de fevereiro de 2019 Aprovado em: 09 de setembro de 2019 